\title{
NOTA-PRÉVIA
}

\section{MÉTODO "IAC" PARA AVALIAÇÃO DO DESEMPENHO DE MÁQUINAS NA CONSTRUÇÃO DE TERRAÇOS}

\author{
Afonso Peche Filho', José Luiz Duarte Coelho², Antônio Carlos Loureiro Lino ${ }^{3}$; \\ Ila Maria Corrêa ${ }^{4}$, José Valdemar Gonzalez Maziero ${ }^{5}$, Kiyoshi Yanai ${ }^{6}$ \\ e José Augusto Bernardi ${ }^{7}$
}

\begin{abstract}
RESUMO
Um método para avaliação do rendimento operacional de máquinas na construção de terraços, é apresentado e testado. Segundo este método, os perfis do canal, do camalhão e do original do terreno em cada seção considerada, são obtidos a partir de pontos na sua superfície, espaçados horizontalmente de $0,5 \mathrm{~m}$ e cujas cotas correspondem à distância entre eles e uma linha horizontal de referência, representada por uma régua ou trena. Para levantamento dos perfis, duas estacas são cravadas a uma distância maior que a lar gura do terraço a ser construído entre elas. A evolução da construção do terraço a cada passada do equipamento é caracterizada pelas áreas das seções transversais do canal e do camalhão, obtidos graficamente. A metodologia apresentada, na qual são utilizados nível de precisão, régua graduada ou trena, mira e estacas, foi aplicada na avaliação de construção de terraço por um trator de esteiras, com lâmina frontal, tendo sido os resultados considerados satisfatórios.
\end{abstract}

Palavras-chave: terraceamento, metodologia, camalhão, perfil da seção

\section{“IAC" METHOD FOR EVALUATION OF PERFORMANCE OF MACHINES FOR TERRACE CONSTRUCTION}

\begin{abstract}
A method for evaluation of machine performace for terrace construction is presented and tested. According to this method, the channel, the ridge and the original land profiles for each section are obtained. For profile determination, horizontal reference points spaced at $0.5 \mathrm{~m}$ were used and their respective heights were measured. The dif ferences in height of reference points on the soil surface relative to a horizontal base line made it possible to calculate the cross sectional areas of the channel and the large ridge after each passing of the implement. The suggested methodology was evaluated for terrace making by a crawler tractor and the results obtained were considered satisfactory.
\end{abstract}

Key words: terrace, methodology, large ridge, profile cross section

\section{INTRODUÇÃO}

A construção de terraços altera a superfície do terreno, de acordo com o tipo de terraço previamente escolhido e a evolução de sua construção varia com o tipo de máquina empregada. Para a determinação e/ou avaliação do desempenho de máquinas na construção de terraços, não se dispõe, porém, de métodos padronizados ou consagrados pelo uso prático. Alguns autores

\footnotetext{
${ }^{1}$ Pesquisador Científico, Centro de Mecanização e Automação Agrícola/IAC/SAA, Rod. D. Gabriel PB. Couto km 65, CP 26, CEP 13.20-970, Jundiaí, SP, Brasil, Fone (011) 7392-8155, Fax (011) 7392-8467, e-mail: peche@dea.iac.br

${ }^{2}$ Professor Assistente, Dept. de Eng. Rural/ESALQ/USP, CP 09, CEP 13.418-900, Piracicaba, SP, Brasil, Fone: (019) 429-4165; e-mail:

${ }^{3}$ Pesquisador Científico, Centro de Mecanização e Automação Agrícola/IAC/SAA, e-mail: lino@dea.iac.br

${ }^{4}$ Pesquisadora Científica, Centro de Mecanização e Automação Agrícola/IAC/SAA, e-mail: imcorrea@dea.iac.br

${ }^{5}$ Pesquisador Científico, Centro de Mecanização e Automação Agrícola/IAC/SAA, e-mail: maziero@dea.iac.br

${ }^{6}$ Pesquisador Científico, Centro de Mecanização Agrícola/IAC/SAA, e-mail: yanai@dea.iac.br

${ }^{7}$ Pesquisador Científico, Centro de Mecanização Agrícola/IAC/SAA, e-mail:bernardi@dea.iac.br
} 
propuseram equipamentos e métodos para o levantamento de linhas de superfície de terrenos (perfis). Currence \& Lovely (1970) desenvolveram um dispositivo automático para levantamento de micro-relevo, constituído por uma sonda vertical que se pode deslocar em duas direções perpendiculares, determinando cotas de 4.800 pontos espaçados de 25,4 x 25,4mm. Mitchel \& Jones Jr . (1973) construíram um perfilógrafo semelhante ao descrito anteriormente, que permite o levantamento das cotas de 1.225 pontos, com o mesmo espaçamento; já Schafer \& Lovely (1976) desenvolveram um perfilógrafo também automático, composto de um tripé de tubos de alumínio que suporta um trilho horizontal, no qual se desloca um carro com uma sonda vertical, enquanto o or ganizado por Henry et al . (1976) mais simples, serve para levantamento dos perfis com $2,00 \mathrm{~m}$ de comprimento e mede as cotas de 100 pontos da superfície do solo a cada posicionamento.

Souza (1972) e Lanças (1988) utilizaram, em seus trabalhos, os perfilômetros conhecidos como "varetas", que consistem em uma barra horizontal com furos igualmente espaçados, nos quais são colocadas réguas que se deslocam verticalmente, levantando perfis de até 1,40 a $1,80 \mathrm{~m}$, respectivamente. Dallmeyer et al. (1987) construíram um perfilógrafo para levantamento do volume de solo mobilizado por mecanismos de semeadura direta, que consiste em um quadro de madeira de $0,80 \times 1,20 \mathrm{~m}$ fixado a colunas com altura de $1,20 \mathrm{~m}$ e dotado de dispositivo para assegurar a sua verticalidade e horizontalidade, ao qual foi fixado um pantógrafo. Após a passagem da semeadora, o perfilógrafo era colocado transversal à direção de deslocamento da máquina traçando, em escala 1:5, o perfil da superfície do solo revolvido e, após a retirada deste solo, o perfil do fundo do sulco. Souza et al. (1988) na determinação do perfil do solo mobilizado pela ação de subsoladores, utilizaram chapas de vidro graduadas, colocadas em trincheiras abertas transversalmente aos sulcos, obtendo o desenho do perfil por transparência.

As citações mencionadas, quando não se referem a perfilógrafos bastante sofisticados, destinados ao levantamento de micro-relevos em laboratório, referem-se ao uso de perfilômetros que, embora de boa aplicação em campo, são limitados no comprimento do perfil levantado.

Ao estudarem a construção de terraços por máquinas e implementos disponíveis no país, Peche Filho et al. (1989) constataram a inviabilidade da utilização dos dispositivos descritos, para acompanhar a marcha de construção dos terraços. O levantamento de perfis, que no caso do uso de terraceadores atingia mais de $9,0 \mathrm{~m}$, compreendendo o canal e o camalhão do terraço, determinou a elaboração do método aqui apresentado e proposto para futuros trabalhos similares. Em geral, a construção de terraço é caracterizada por parâmetros, como: seção final do terraço (perfil gráfico/esquemático), rendimento da operaçã o $(\mathrm{m} / \mathrm{h})$, largura do terraço $(\mathrm{m})$ e altura do camalhão $(\mathrm{m})$ mas, quando se quer avaliar ou comparar o desempenho de diferentes máquinas na construção de terraços, é preciso levar-se em consideração, também, as suas etapas de formação.

O objetivo deste trabalho, é, portanto, apresentar um método para avaliação do desempenho de máquinas na construção de terraços, com base no acompanhamento das suas etapas de construção.

\section{MATERIAL E MÉTODOS}

Para se fazer as medições em campo, foram utilizados: nível de precisão, mira, trena ou corrente de agrimensor , estacas e cronômetro. Para levantamento do perfil, duas estacas são cravadas a uma distância maior que a lar gura do terraço a ser construído entre elas, e com o auxílio do nível de precisão e da mira, são marcados nas estacas pontos de referência R, (Figura 1) no mesmo nível, a alturas, a partir do solo, maiores que a altura máxima do futuro camalhão. As cotas desses pontos e a distância entre as estacas permitem o cálculo da declividade entre elas.

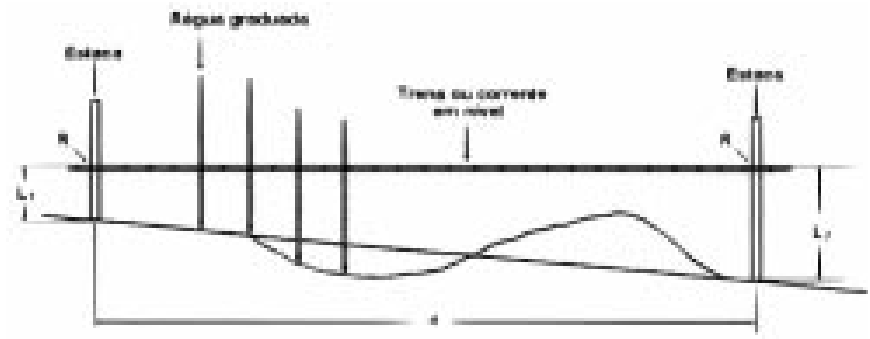

Figura 1. Esquema de levantamento do perfil do terraço

$$
D=\frac{L_{2}-L_{1}}{d} x 100
$$

em que:

D - Declividade (\%)

$\mathrm{L}_{1}$ - Cota da marca na primeira estaca $(\mathrm{cm})$

$\mathrm{L}_{2}$ - Cota da marca na segunda estaca $(\mathrm{cm})$

d - Distância entre as estacas $(\mathrm{cm})$

Uma trena ou corrente de agrimensor é estendida entre as marcas, em nível das estacas, sustentadas por duas pessoas. Antes do início da construção do terraço, é levantado o perfil da superfície do terreno, por meio do deslocamento de uma mira ou régua graduada, a intervalos regulares ao longo da trena (Figura 1); feito este levantamento inicial, a trena é retirada e se procede à primeira passada da máquina de construção do terraço; então, a trena é novamente estendida entre as estacas e se executa o levantamento do perfil do terreno movimentado, tomando-se leituras de cota de $0,5 \mathrm{em} 0,5 \mathrm{~m}$, a cada passada da máquina, as quais são anotadas em planilha adequada (Figura 2). As cotas, lidas por meio de cálculo, fornecem as áreas da seção transversal do canal e desenhos em escala podem ser elaborados, permitindo a visualização da seção transversal do terraço, a cada passada; pode-se, então, por planimetria, obter maior facilidade na determinação das seções do canal e do camalhão.

A seção do canal a cada passada, marcada em um gráfico, permite também acompanhar a marcha da construção do canal, enquanto durante as passadas é cronometrado o tempo necessário para a máquina percorrer uma distância previamente marcada no terreno, com o que se obtém a velocidade média do deslocamento, utilizada para calcular o rendimento da operação, em comprimento de terraço por unidade de tempo. Complementando o trabalho de campo, devem ser caracterizadas, também, as condições da área, em termos de topografia, tipo de solo, resistência à penetração, análise de agregados, taxa de infiltração de água e teor de água do solo. 


\begin{tabular}{|c|c|c|c|c|c|c|}
\hline \multicolumn{4}{|c|}{ Terrapo $n^{n}: 12$} & \multicolumn{3}{|c|}{ Local - Usins Cods Piato } \\
\hline Trator: & \multicolumn{3}{|c|}{ Canciflar DSB } & \multicolumn{3}{|c|}{ Drate $4 / 688$} \\
\hline \multicolumn{4}{|c|}{ Implemento. Lamina Lo } & \multicolumn{3}{|c|}{ Dechividade: $4699^{2}$} \\
\hline \multirow{3}{*}{$\begin{array}{c}\text { Distancia } \\
\text { (m) }\end{array}$} & \multicolumn{6}{|c|}{ Letura na mins $(\mathrm{cm})$} \\
\hline & \multicolumn{6}{|c|}{ Pasuatan } \\
\hline & 0 & 1 & 2 & 3 & 4 & 5 \\
\hline 00 & $\overline{70}$ & 76 & 74 & 75 & 74 & 73 \\
\hline 05 & 71 & 70 & 6 & 68 & 67 & 68 \\
\hline 1.0 & क0 & 68 & 67 & 72 & 7 & 72 \\
\hline 1.5 & 65 & 76 & 73 & 73 & 67 & 68 \\
\hline 2,0 & 69 & 90 & \$ & 81 & 76 & 69 \\
\hline 25 & 7 & 82 & 84 & 87 & 78 & 91 \\
\hline 3,0 & 76 & 91 & 104 & 100 & 96 & 98 \\
\hline 3,5 & 76 & 95 & 104 & 105 & 56 & 101 \\
\hline 4,0 & 79 & 94 & 110 & 110 & 101 & 107 \\
\hline 4,5 & 76 & 94 & 100 & 114 & 103 & 111 \\
\hline 5,0 & 75 & 167 & 115 & 120 & 114 & 118 \\
\hline 5,5 & 90 & III & 124 & 132 & 121 & 112 \\
\hline 6,0 & 81 & 112 & 124 & 134 & 122 & 114 \\
\hline 6,3 & 79 & 104 & 120 & $\overline{132}$ & 123 & 123 \\
\hline 7,0 & 84 & 96 & 121 & 138 & 131 & 128 \\
\hline 7,5 & 91 & 9 & 124 & 140 & 126 & 130 \\
\hline 8,0 & 93 & 100 & 124 & 138 & 130 & 130 \\
\hline 8,9 & 93 & 101 & 123 & 133 & 124 & 129 \\
\hline 9,0 & 97 & 93 & 190 & 135 & 121 & 128 \\
\hline 9.5 & 101 & 83 & 124 & 133 & 106 & 127 \\
\hline 10,0 & 105 & $\pi$ & 122 & 124 & 93 & 97 \\
\hline 105 & 107 & 73 & 116 & 101 & $\overline{84}$ & 82 \\
\hline 11,0 & 113 & 73 & 90 & 76 & 55 & 9 \\
\hline$\pi 1.5$ & 115 & 70 & 76 & 41 & 26 & 32 \\
\hline 12.0 & 119 & 85 & 63 & 9 & -2 & 4 \\
\hline 125 & 123 & 115 & 26 & -14 & -22 & -250 \\
\hline 130 & 125 & 121 & 21 & 16 & -9 & 9 \\
\hline 13.5 & 128 & 127 & 51 & 48 & 22 & 22 \\
\hline 140 & 130 & 150 & 72 & 70 & 62 & 62 \\
\hline 145 & iw & $1+0$ & 100 & 110 & 126 & 126 \\
\hline 15,0 & 133 & 133 & 134 & 133 & 153 & 133 \\
\hline 15,5 & 138 & 138 & 140 & 145 & 145 & 145 \\
\hline 16,0 & 148 & 148 & 148 & 142 & 162 & 142 \\
\hline
\end{tabular}

Figura 2. Planilha para registro dos dados (preenchida)

\section{RESULTADOS E DISCUSSÃO}

Como exemplo de resultado do método utilizado, é apresentado, na Figura 3, o perfil de terraço tipo "leirão" obtido a cada passada, com trator de esteira marca Caterpillar modelo D5B, equipado com lâmina frontal, em latossolo roxo, com teor de água no solo de $15 \%$ (b.u.) e declividade de $4,7 \%$. Segundo CAIC (1987) o terraço tipo "leirão" é construído, em média, com quatro laminadas frontais, as quais levantam o camalhão a uma altura de $1,80 \mathrm{~m}$ aproximadamente.

No caso do exemplo, verificou-se que na quarta passada da máquina foi definida a seção transversal final do terraço, tendo o camalhão atingido $1,45 \mathrm{~m}$ de altura; a velocidade média de deslocamento da máquina foi de $4,83 \mathrm{~km} / \mathrm{h}$.

Na Figura 4 é destacada a seção transversal do terraço, que evoluiu de $2,72 \mathrm{~m}^{2}$ primeira passada, até $23,56 \mathrm{~m}^{2}$ na quarta passada. quinta passada, como se vê, não havia necessidade de ser realizada, pois a altura do camalhão e a seção do canal se mantiveram praticamente constantes.

\section{CONCLUSÃO}

Com material de baixo custo normalmente utilizado em qualquer ensaio de campo, foi possível executar-se o método apresentado, com resultado adequado, para finalidade de acompanhamento das etapas de construção de terraços.

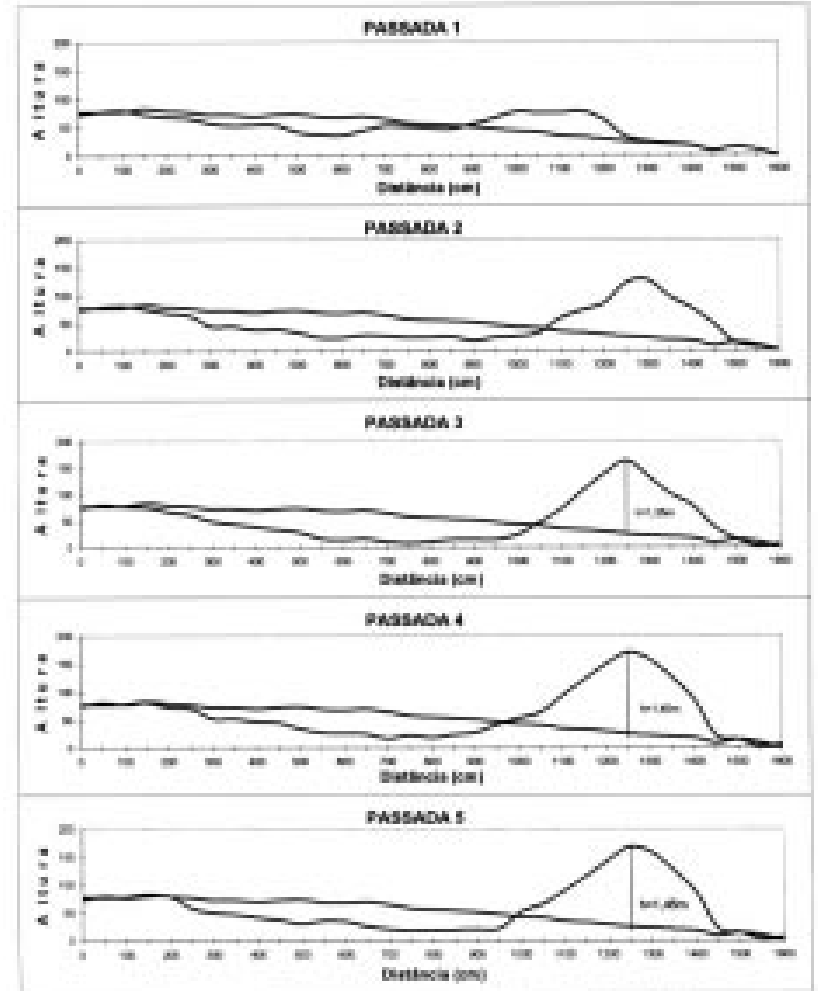

Figura 3. Seqüência das seções transversais do terraço a cada passada da máquina

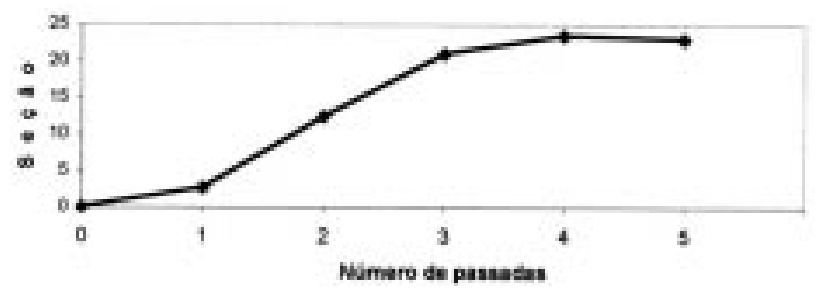

Figura 4. Seção transversal do terraço em função do número de passadas

\section{REFERÊNCIAS BIBLIOGRÁFICAS}

CAIC - COMP ANHIA AGRÍCOLA IMOBILIÁRIA E COLONIZADORA. Conservação do solo em microbacias. São Paulo: CAIC, 1987. 41p. (Boletim Técnico)

CURRENCE, H.D.; LOVELY, W.G. The analysis of soil surface roughness. Transactions of the ASAE, v. 13, p.710-714, 1970

DALLMEYER A.U.; RIGHES, A.A.; POZZERA, J.; FERREIRA, O.O.; SIL VEIRA, T.C.; SILVEIRA, D.R.; FARRET, I.S. Mobilização do solo por mecanismos de semeadura direta. In: CONGRESSO BRASILEIRO DE ENGENHARIA AGRÍCOLA, 15., 1986, São Paulo: Anais... Sociedade Brasileira de Engenharia Agrícola, 1987, p.155-156.

HENRY, J.E.; V AN DOREN Jr ., D.M. SCIARINI, M.J. A device for automatically measuring transects of soil surface contours. In: INTERNA TIONAL CONFERENCE ON MECHANIZATION OF FIELD EXPERIMENTS, 4. Ames, Iowa, 1976, Proceedings. p.282-292. 
LANÇAS, K.P. Subsolador: desempenho em função de formas geométricas de hastes, tipos de ponteira e número de hastes. Botucatu, Faculdade de Ciências Agrárias/ UNESP, 1988, 171p. Tese Doutorado

MITCHEL, J.K.; JONES Jr, B.A. Profile measuring device. Transaction of the ASAE. v.16,p. 546-547, 1973.

PECHE FILHO, A.; MENEZES, J.F . de; COELHO, J.L.D.; MAZIERO, J.V.G.; YANAI, K.; PECHE, A.TM.; CORRÊA, I.M.; BERNARDI, J.A. Construção de terraços: máquinas e equipamentos disponíveis no Brasil. In: SIMPÓSIO SOBRE TERRACEAMENTO AGRÍCOLA, 1989, Campinas:Anais, Fundação Cargill, 1989, p.136-167.
SCHAFER, R.L.. LOVELY, W.G. A recording soil surface profile meter. Agricultural Engineering, St. Joseph, v.48, p. 280-282, 1976.

SOUZA, A.P. Efeito da velocidade de operação do arado de discos de arrasto, na componente longitudinal do esforço tratório. Piracicaba: ESALQ/USP, 1972, 54p. Dissertação Mestrado

SOUZA, F .L.C.; TREIN, C.R.; CAMP ANI, D.B. Determinação do perfil do solo mobilizado pela ação do subsolador. In: CONGRESSO BRASILEIRO DE ENGENHARIA AGRÍCOLA, 16, 1987, Jundiaí:Anais... Sociedade Brasileira de Engenharia Agrícola, 1988. v .2, p.329-336. 